University of St. Thomas, Minnesota

UST Research Online

$1-2015$

\title{
The expression of espoused humanizing values in organizational practice: A conceptual framework and case study
}

Brian P. Shapiro

University of St. Thomas, Minnesota, BPSHAPIRO@stthomas.edu

Michael Naughton

University Of St. Thomas - Minnesota, mjnaughton@stthomas.edu

Follow this and additional works at: https://ir.stthomas.edu/ocbacctpub

Part of the Accounting Commons

This Article is brought to you for free and open access by the Accounting at UST Research Online. It has been accepted for inclusion in Accounting Faculty Publications by an authorized administrator of UST Research Online. For more information, please contact asle4660@stthomas.edu. 


\title{
The Expression of Espoused Humanizing Values in Organizational Practice: A Conceptual Framework and Case Study
}

\author{
Brian Shapiro • Michael Naughton
}

Received: 13 January 2013/ Accepted: 29 November 2013/Published online: 17 December 2013

(C) Springer Science+Business Media Dordrecht 2013

\begin{abstract}
We provide a conceptual framework and a case study of how an organization links its mission and espoused values with its operating practices. Conceptually, we locate this mission integration theme within Simons' (1995, Levers of control. Harvard Business Review Press, Boston) management accounting and control framework, and then adapt Schatzki's (2002, The site of the social. Pennsylvania State University Press, University Park) site ontology of social practice to develop general research expectations for case studies of espoused values/practice linkages. Empirically, we apply the conceptual framework to a case study of linkages among an actual company's espoused values, human resource practices, and financial management during its 40-plus year history. The concluding section summarizes the study and discusses its implications, limitations, and opportunities for future research.
\end{abstract}

Keywords Tone at the top · Humanizing organizations . Practice theory $\cdot$ Ethics

The conventional way of business practice is wrong. People are relating to each other in ways that are not healthy,... not serving the common good. In the long run, not even serving economic interests at all.... I think we can benefit as a society and as individuals just if we have the courage to try things. If we only try them because we can see somebody else is making

\footnotetext{
B. Shapiro $(\bowtie)$

Department of Accounting, UST Opus College of Business, University of St. Thomas, 2115 Summit Avenue, Mail \# MCH 316, St. Paul, MN 55105-1096, USA

e-mail: bpshapiro@stthomas.edu

M. Naughton

John A. Ryan Institute for Catholic Social Thought, University of St. Thomas, 2115 Summit Avenue, 55S, St. Paul, MN 55105, USA

e-mail: mjnaughton@stthomas.edu
}

money with it that's not going to get $u$ s in the right place. (Bob Wahlstedt, board member and retired founding executive of Reell Precision Manufacturing, Inc., August 16, 2012 interview with authors).

\section{Introduction}

The enterprise risk management (ERM) and management accounting literatures recognize that an organization's espoused values (and other components of its internal environment or "tone at the top") can shape virtually everything that management does to manage risk and achieve the organization's strategic and operating objectives (e.g., Committee of Sponsoring Organizations (COSO) 2004, pp. 27-40; Simons 1995, Chap. 3). Those literatures have not, however, been very specific about how an organization's espoused values might shape or become embedded in its practices. Consequently, our knowledge of the relation between espoused values and practices is limited. To fill this void, we provide a conceptual framework for theorizing about values/practice linkages in general, and then describe a case study of how an actual forprofit organization attempts to live out its espoused values in its everyday practices.

This study's conceptual and case studies are motivated by three factors that arguably constrain how values/practices linkages tend to be framed in the ERM and management accounting literatures. First, the ERM literature emphasizes the objectives of efficiency and profit maximization (e.g., COSO 2004, p. 35) and devotes little attention to other business objectives such as employee development and the provision of socially beneficial goods and services. The ERM's restricted focus suppresses the range of espoused values that can be conceptually and analytically entertained in studies of mission integration within organizations. We address this limitation by considering a 
broader set of espoused values that organizations might hold while engaging in profit-seeking activities. More specifically, our working premise is that humanizing values ${ }^{1}$ (in addition to operational and accounting expertise) are necessary for organizations to engage in ethical practices. A humanizing requirement is necessary because it encourages the kinds of values/practices integration that are likely to yield beneficial social outcomes, and it rejects values/ practice linkages that are likely to yield adverse social outcomes.

Second, some widely promulgated codes of ethical business conduct prescribe general guidelines for achieving sustainable, fair, and transparent business objectives [e.g., Caux Round Table 2010; Organization for Economic Cooperation and Development (OECD) 2008], and thereby overcome the ERM literature's limited objectives, but the codes offer few specific examples of how actual organizations might achieve the expanded set of objectives through their operating practices. ${ }^{2}$ We address this limitation by describing detailed examples from a case study of how an actual for-profit organization has attempted to live out its values in its human resource practices during its 40-plus year history. The subject of our case study is Reell Precision Manufacturing, Inc. (hereafter, Reell), a small to medium size, privately held manufacturer of precision components headquartered in the mid-western United States with offices in China and the Netherlands. ${ }^{3}$ We selected Reell because its espoused values aim to create a humanizing organizational culture. In addition, previous case studies of Reell have indicated that many of its practices reflect its espoused values. Moreover, Reell received the Minnesota Business Ethics Award in 2003 and the National Business Ethics Award in 2004 as further external recognition of its ethical business practices, in

\footnotetext{
${ }^{1}$ Humanizing values respect the dignity of persons, promote care and service for others, support the personal and professional growth of employees and their families, advance the common good, and are committed to doing what is right even when it does not seem profitable or expedient (cf. the definition of "humanizing organizational culture" in Mele 2003, p. 3).

${ }^{2}$ For example, one OECD guideline states "Encourage human capital formation, in particular by creating employment opportunities and facilitating training opportunities for employees," but it does not specify how an organization might effectively translate those general ideas into specific practices.

${ }^{3}$ Reell's products include standard and custom hinges, wrap spring clutches, torque inserts, precision springs, and wire forms. Like many other for-profit business organizations, Reell has experienced structural and personnel changes in senior management, competitive market pressures, and periods of growth and contraction throughout its more than 40-year history. Reell grew from its original three founders and a few employees in 1970 to approximately 130 employees in 2012. It implemented an employee stock ownership plan in 1986. As of 2012 company employees owned $49 \%$ of company stock and will soon be majority owners.
}

particular for its efforts to avoid layoffs even during prior periods of business contraction and declining profit.

Third, the management accounting and control literature recognizes that an organization's espoused values and codes of conduct shape how agents attempt to achieve their organization's objectives (e.g., Simons 1995, Chap. 3), but does not address in detail the linkages that might exist among an organization's values, operating rules, and practices. We address this limitation by advancing a conceptual framework for theorizing about values/practices linkages within organizations. Specifically, we adapt Schatzki's $(2002,2003,2005)$ site ontology of social practice to develop general research expectations for case studies of espoused values/practices linkages, and then apply the framework to our case study of Reell. The ontological dimension of Schatzki's framework identifies the values, shared understandings, rules, instrumental objectives, and other components that organize activities into a practice. These components describe the kinds of phenomena that will be encountered in field studies. The site dimension of Schatzki's framework defines a site as a special type of context whose components can both shape and be shaped by the site and the other components. A practice is an example of this kind of site because a practice provides a context for organizing the activities and the other components that constitute the practice. Schatzki's site ontology is relevant for a study of values/practices linkages because it posits that an organization's values (espoused or otherwise) are integral components of its practices. Within this framework, the task for a field investigation is to document the organization's values and how they are embedded in its practices.

The remainder of the paper is organized in four sections. The first section locates the study's theme of espoused values within Simons' (1995) management accounting and control framework, and then adapts Schatzki's (2002, 2003, 2005) site ontology of social practices to develop general research expectations about the kinds of valuespractices linkages that might be found in field studies of organizations. The second section describes our case study method, data, and the specific research questions that guided our data gathering and analysis. The third section describes and analyzes Reell's espoused values and their relation to Reell's human resource and financial management practices. The concluding section summarizes the study and discusses its implications, limitations, and opportunities for future research.

\section{A Conceptual Framework of Espoused Values and Their Relation to Practice}

This section provides a conceptual framework for theorizing about how an organization's espoused values may be 
integrated within its operating practices. We first locate the themes of espoused values and organizational practices within Simons' (1995) management accounting and control framework of organization design. We then adapt Schatzki's $(2002,2003,2005)$ site ontology of social practices to develop general research expectations for case studies of values/practices integration in actual organizations.

\section{Levers of Control in Organizations}

Simons (1995) proposed that four systems comprise levers of control help agents achieve their organization's strategic objectives. Two systems relate directly to this study's concern with espoused values: belief systems (values, purpose, and direction) and boundary systems (formal rules, prescriptions, and proscriptions linked to the credible threat of sanctions). These two systems typically are articulated in an organization's mission statements, vision statements, and codes of conduct. Together, the belief and boundary systems specify the values, beliefs, and range of acceptable behaviors that support the organization's objectives. The other two systems in Simons' (1995) framework relate more directly to an organization's practices: diagnostic control systems (feedback systems to monitor outcomes and correct deviations from performance standards) and interactive control systems (whereby managers periodically engage with the decision activities of subordinates and communicate system-generated data to enable subordinates to better achieve the organization's objectives). The diagnostic and interactive control systems comprise institutionalized activities to help managers and other agents communicate about and control their organization's attempts to put its values into practice.

Each management control system must be tailored to fit the other systems. In Simons' (1995) framework, strategy and the formal levers that managers use to transmit and process information are the glue that holds the systems together. Nevertheless, questions remain about how an organization's belief and boundary systems shape and are shaped by the diagnostic and interactive control systems, and how the four systems are integrated with the other components of an organization's operating practices. In addition, unlike in the COSO (2004) Enterprise Risk Management Framework, Simons' (1995) framework conceptualizes internal control systems as support systems to help the organization safeguard its assets and provide reliable financial data, but they are not also conceptualized as integral components of the organization's other practices. As described below, Schatzki's (2002, 2003, 2005) site ontology provides a more complete conceptual framework for theorizing about the interrelated components of organizational practices.

\section{Schatzki's Site Ontology of Social Practices}

Schatzki's ontology is relevant to this study's focus on values/practices linkages because it describes how norms, rules, and resources can shape and organize the activities that comprise a practice. ${ }^{4}$ Schatzki's site ontology is similar to other site ontologies in that it contends that organized human activities are inherently tied to the context in which they occur. In addition, like other practice theories Schatzki's framework conceptualizes how social life in organizations also is constrained or enabled by available material, financial, and abstract arrangements. Unlike most other practice theories, Schatzki's ontology uses the network metaphors of "meshes," "bundles," and "nets" to highlight the linkages that bind together the various entities in his ontology. For example, in his framework, "practicearrangement meshes" refer to networks of organized activities and resources that enable or constrain the activities that comprise the practice in question.

The following subsections further describe Schatzki's definition of practice, practice-arrangement meshes sites as a context within which a practice's components are located, and how values/practices linkages may be interpreted and negotiated by interested parties. Each subsection also develops general implications for field studies of values/ practices linkages.

\section{Practices as Organized Activities}

In Schatzki's site ontology, practices are comprised of "organized human activities." For example, human resource practices include employee hiring, training and development, performance evaluation, promotion, and firing activities. The set of activities that can make up a given practice at a given location in time and space is open-ended and may be subject to change and negotiation. Field studies of organizational practices need to identify the significant activities that comprise the practices and how the activities may vary across time and space within the organization.

Furthermore, three components link and organize the activities that comprise a practice: (a) shared understandings about the actions (Schatzki 2003, p. 191), (b) explicit rules that prescribe or require how things must be done or said (Schatzki 2005, p. 471), and (c) a "teleoaffective structure" that consists of ends, projects, uses of things, and perhaps a range of acceptable or prescribed emotions (Schatzki 2005, pp. 471-472). In other words, the organized

\footnotetext{
${ }^{4}$ Some accounting researchers have used Schatzki's practice theory to examine management accounting practice (e.g., Ahrens and Chapman 2007), while others have used Giddens' structuration theory (for a review, see Englund et al. 2011). For comparisons of Schatzki's ontology with other sociological theories, see Schatzki (1997; 2002, pp. xii-xiii; 2003, pp. 174-177).
} 
actions that comprise a practice "express the same understandings, observe the same rules, or pursue ends and execute projects...[whose] end project-task combinations....are acceptable or prescribed" (Schatzki 2003, p. 192; see also Schatzki 2005, p. 472). The components that organize activities may be established internally (e.g., through mission statements, vision statements, and company policies) or imposed externally (e.g., through business regulations, accounting regulations, and external audits). To illustrate with a business example, human resource practices consist of actions linked by shared understandings and rules about how to hire, promote, train, retain, and fire employees; and task-project combinations that deploy human resources to achieve organizationally determined acceptable ends. Normatively acceptable human resource practices will among other things conform to the organization's employee handbook, social norms of expected behavior, and applicable federal, state, and local regulations.

To summarize, Schatzki's ontology posits that practices are comprised of shared understandings, rules, and acceptable ends toward which agents carry out their activities in pursuit of the organization's objectives. Field studies of practices thus need to document these components. In an organization whose agents effectively "walk the talk," the components of the organization's practices will reflect the substantive commitments that are expressed in the organization's espoused values. In this case, a field study might for example document that a practice yields outcomes that are reasonably consistent with the substantive values in the organization's mission and belief statements, or that the practice explicitly refers to the values and thereby reinforces and is shaped by them. In contrast, if an organization's practices violate its espoused values, a field study might document how the organization's espoused values differ from its operative values.

\section{Practice-Arrangement Meshes}

An agent's ability to carry out her activities to support her organization's objectives will also depend on the available resources. Accordingly, the social actions and interactions that comprise an organization's activities take place within what Schatzki calls a "mesh of practices and arrangements" (Schatzki 2003, pp. 191-192). For a given practice, the relevant organizational arrangements might include the various material, financial, and abstract (non-spatial/temporal) resources necessary to support the activities. For example, an organization's human resource practices might be enabled or constrained by the financial resources provided by its internal operations, external lending practices, and external competition. The implication is that in order to evaluate and explain the extent to which an organization is able to effectively live out its values, field studies must identify the resources that support or constrain the organization's practices. In some cases, the essential resources may be generated by other practices. For example, the financial resources that enable an organization to provide the job security and compensation that it aspires to provide for each employee might depend on the outcomes of other internal and external operating and financial practices.

\section{Practices as Sites}

In Schatzki's framework, sites are where the components of practices are located, and are a special type of context wherein "context and contextualized entity constitute one another" (Schatzki 2005, p. 468). Practices are an example of this special type of context because they are the site of the organized activities and associated components that both shape and are shaped by the practices.

The mutually constitutive roles of values, activities, and practices can be illustrated with an example of mission drift. Suppose that an organization's espoused values initially shape the activities that its agents perform, such that the organization's espoused and operative values converge. Later in time, the components that link and organize actions may undergo change as new personnel, arrangements, and other circumstances emerge, and these changes may in turn alter the practices (Schatzki 2005, p. 478). The important issue is whether an altered practice still conforms with the organization's espoused values. This issue is further complicated by how the set of actions that can constitute a practice is open-ended, and how the set of understandings, rules, and acceptable ends that link and organize actions may be larger than the specific versions that exist in individual agents' minds at a particular time and place (cf. Schatzki 2003, p. 194).

An implication is that not every observable change in practices will necessarily violate the organization's espoused values. Externally, interested parties may determine through evidence, deliberation, and debate whether the organization's altered practices reasonably conform to its normative and prescriptive commitments (cf. Schatzki 2005 , p. 475). Internally, the organization's agents might design and use formal or informal interactive and diagnostic control systems to monitor, deliberate over, and manage the conformity between the organization's activities and its espoused values (cf. Simons 1995, Chaps. 4-5). In Schatzki's ontology, the interactive and diagnostic control systems can be integral to the activities that comprise the practices, rather than only be imposed externally. For example, human resource practices might include such activities as annual performance reviews, employee recognition events, and opinion surveys to gauge how well the organization lives out its espoused values. 


\section{Methods}

A site ontology investigation involves documenting what Schatzki (2003, pp. 197-198) calls practice-arrangement bundles (organized activities and the resources that support them) and constellations of related bundles. While Schatzki (2003, p. 198) applied his framework to detailed chains of human and nonhuman action, this study's research objectives do not require such microanalyses. ${ }^{5}$ Our case study of Reell instead provides overviews of Reell's human resource practices and the financial and abstract resources (e.g., espoused values) that have shaped those practices throughout the company's history. This section describes the methods, research questions, and components of Schatzki's ontology that we applied to the Reell's case study.

The case study's data were culled from previously published case studies of Reell, the company's Web site, internal company documents, interviews with one former and three senior executives, and annual coworker survey data. The fieldwork comprised informal and formal interviews, document collection, and data interpretation and analysis. The second author's dual roles as university professor and Chair of Reell's Board of Directors provided a deep familiarity with Reell's personnel and its strategic and operating objectives and policies, and facilitated access to participants and documents. Berg (2004, p. 160) similarly reported an increasing trend whereby researchers "create research teams that include, as members, insiders from the group or groups to be studied" (emphasis in the original). While the second author's dual status might raise questions about researcher objectivity or critical distance from the objects of study (cf. Gendron and Barrett 2004, p. 574), the second author's dual status also enabled our access to sensitive company data that would not otherwise be available from this privately held company. In addition, we support the study's primary conclusions with multiple examples and other data that were publicly available before the second author joined the Reell board and before we commenced our research.

\footnotetext{
5 Indeed, as Schatzki (2005, p. 477) put it:

Often...investigators do not need to track and register the potentially labyrinthine complexity of bundles, nets of bundles, and so on. In many cases, it is desirable and feasible to provide overviews of social phenomena and their workings that are couched in terms referring, not to the details of practicearrangement bundles, but to entire formations and their relations...The present point is that, at whatever scale and with whatever conceptual apparatus social affairs are studied, social phenomena, ontologically, are aspects or nets of practicearrangement bundles (Schatzki 2005, p. 477, emphasis in the original).
}

Previous Case Studies of Reell

We obtained historical background and initial familiarity with Reell's espoused values and human resource policies from previously published case studies by Goodpaster (1999), Goodpaster and Naughton (2004, 2005), Herrera (2006), Naughton and Specht (2011, pp. 15-51), and Wahlstedt's (undated) history of Reell. Unlike in our study, the previous case studies did not draw from a social theory or conceptual framework of practices, nor did they attempt to generalize from Reell's experience to the governance, enterprise risk management, and management accounting literatures. In addition, as described next, our study incorporates more recent Reell documents and practices, and it more systematically documents and analyzes how Reell's espoused values are enmeshed in its practices.

\section{Company Documents}

In the course of our investigation we examined the following documents: Reell's Direction Statement; Belief Statement; 2011 Board Retreat presentation (Wahlstedt 2011); inspirational documents used at the beginning of Reell leadership and board meetings; Coworker Policy Manual (Reell 2009); Annual Conference Review forms (Reell 2007, 2011a); job descriptions for the Vice President of Coworker Services, Executive Administrator, and Buyer; the company's Founders' Award Process (Reell undated), Founders' Award Application Form (Reell 2011b), past Founders' Award nominations; a copy of the annual board-directed Reell coworker survey which is administered voluntarily and anonymously via Survey Monkey; the 2012 survey data; and management's 2012 survey discussion and trend analysis which it shared and discussed at meetings with company coworkers. We examined these documents for traces of the company's espoused values and sought other evidence of their impact on the company's everyday practices and coworkers' perceptions.

\section{Interviews}

Five face-to-face interviews with one retired executive/ company cofounder and three current executives took place over a 15-month period from December 2011 through March 2013. This interview emphasis on company executives is appropriate given this paper's focus on the tone at the top and executives' leadership role in shaping organizational practices. Each interview was audio recorded and lasted approximately $1 \mathrm{~h}$. The study's first author attended all five interviews, asked the interview questions, moderated the discussion, and transcribed the audio recordings. The study's second author helped arrange and attended 
interviews 1-3 and 5. The general interview objectives were to assess everyday life at Reell, document the relations between Reell's espoused values and practices as seen from the perspectives of the interview participants and other coworkers, and identify and obtain access to relevant company documents and records. Both authors met privately before each interview to translate the study's general research questions into specific interview objectives and questions. The specific objectives, questions, and interview content varied across the interviews.

The purpose of the study was transparently communicated to the interviewees, and no deception was used to gain access to interviewees and company data. The study's Consent Form listed the project title as "The reciprocal roles of spiritual traditions, accounting, and the evolving human resource practices at Reell Precision Manufacturing, Inc.," and it stated that the purpose of the study was "to document how Reell's spiritual commitments in its Direction Statement and Reell's accounting and management practices both shape, and are shaped by, Reell's human resource practices."

The first formal interview took place at the Reell headquarters in December 2011, lasted 75 min, and was attended by the study's authors, current CEO Kyle Smith, and Vice President of Coworker Services Ken Rude. The purpose of this interview was to establish the research protocol and agreement about the study's scope and focus. We used an iterative technique similar to "snowballing" (Berg 2004, p. 36) in this and the subsequent interviews to develop follow-up questions, request access to additional company documents mentioned during the interviews, identify future interviewees, and plan the next interviews. Between interviews we used follow-up phone calls and email messages to obtain documents and request clarifications. Reell executives provided all requested company documents.

The second interview took place at the Reell headquarters in June 2012 with Ken Rude. The interview scope included identifying the human resource policies, practices, and documents that demonstrate how Reell attempts to live out its spiritual principles. The third interview lasted 80 min and was held in August 2012 at the authors' university with Bob Wahlstedt (one of the three retired Reell founding executives, and the primary author of Reell's Belief Statement). The scope of the interview included the challenge of discerning how to translate the Direction Statement's spiritual principles into company policies and everyday practices, in an inclusive manner so that all employees can find the principles accessible, acceptable, and personally meaningful. The fourth interview lasted 60 min and was held in October 2012 with Kyle Smith (CEO) at the Reell headquarters. Interview topics included Kyle's collaborative leadership style, the conditions and arrangements that made his leadership style both necessary and possible, the relation between the Direction Statement's four spiritual principles and Reell's policies and day-to-day practices, his reflections on past mistakes the company had made in applying the spiritual principles to its human resource and financial management practices, and strategies he has subsequently led to avoid similar problems in the future.

The fifth interview lasted 60 min and was held in March 2013 with Shari Erdman, the Reell Director of Global Coworker Services. ${ }^{6}$ The interview focused on executive hiring practices, employee perceptions about the company's espoused values, and board-directed annual employee surveys administered voluntarily and anonymously through Survey Monkey.

\section{Research Questions for the Reell Case Study}

Schatzki's site ontology, our previous familiarity with Reell, and our research objectives guided the following research questions and data analysis:

1. What are Reell's espoused values, in which company documents and locations are they articulated, and how are they communicated to employees throughout the firm? These questions relate to the formal communication of abstract rules, teleoaffective structures, and shared understandings in Schatzki's (2002, 2003, 2005) site ontology of social practices. The questions also relate to the belief systems and boundary systems in Simons' (1995) management accounting and control framework.

2. What kinds of evidence indicate that the espoused values shape Reell's human resource activities? Schatzki's ontology posits that espoused values and shared understandings will be internal to (embedded in) the activities that comprise practices. This implies that some of Reell's human resource activities might refer directly to the espoused values, and that some agents in the organization might periodically reflect on those values when they carry out their activities in pursuit of the organization's objectives. In addition, the diagnostic control systems and interactive control systems in Simons' (1995) framework suggest that Reell's managers will carry out human resource activities to gather and evaluate data to monitor the organization's progress toward putting its values into practice, and will periodically communicate those data to their subordinates. Finally, other evidence might

\footnotetext{
${ }^{6}$ Shari assumed Ken's human resource responsibilities in early 2013. Ken left Reell to continue his career at his former employer whose President asked him to return as Senior Director of Human Resources and help rebuild the company's culture.
} 
indicate the extent to which Reell's human resource practices produce outcomes that are consistent with the espoused values.

3. How have financial and other resources enabled or constrained Reell's human resource practices, and how have other internal or external practices determined the amount of available resources? These questions address the "mesh of practices and arrangements" in which activities take place in organizations (Schatzki 2003, pp. 191-192), and recognize that some practices shape and others are shaped by organizational arrangements (cf. Schatzki 2005, p. 468).

4. What past mistakes have Reell's managers made in putting the espoused values in practice, and how has reflection on those mistakes shaped Reell's subsequent human resource and financial management practices? These questions address the relation between belief and diagnostic control systems in Simons' (1995) control framework.

5. How do Reell's lower level coworkers perceive the impact of the company's espoused values on their work and personal life? These questions relate to how the shared understandings, rules, and teleoaffective structures that organize activities into practices may vary over time and space (Schatzki 2005, p. 478), and how they may be interpreted, deliberated, and negotiated by interested parties (Schatzki 2005, p. 475).

\section{Reell's Espoused Values in Practice}

Below we first describe and analyze the company documents that express Reell's espoused humanizing values, how the values are communicated throughout the organization, and how Reell's executives perceive and interpret the values. We then examine how the values shape and are reinforced by Reell's human resource practices, how available resources shape those practices, and survey evidence of how Reell's lower level coworkers perceive the company's values and practices.

\section{Reell's Humanizing Values and Beliefs: Company Documents and Management's Perceptions}

We begin by addressing our first research question, which asks "What are Reell's espoused values, in which company documents and locations are they articulated, and how are they communicated to employees throughout the firm?" Reell's espoused values have evolved over its 40-year history from a startup homogeneous company to a small to medium size pluralistic company. The values came from the spiritual commitments of the founders who sought to develop a business where people could grow in an integral way. As the company grew, the language for expressing those values evolved away from the founders' Christian commitments to a spiritual and moral language that could accommodate the pluralism of the other coworkers who joined them. The company's values may be described as "humanizing" inasmuch as they aspire toward the following properties of "organizational humanizing cultures" set forth by Mele (2003, p. 5):

1. Recognition of the person in his or her dignity, rights, uniqueness, sociability and capacity for personal growth.

2. Care and service for persons around one.

3. Management toward the common good versus particular interests.

Consistent with these humanizing objectives, Reell's founding principles put a priority on earning a living, growing personally and professionally, being able to put family first, and integrating faith and work (Naughton and Specht 2011, p. 18, 19; Wahlstedt, undated). The goal of advancing the security and growth of coworkers was grounded in the founders' experience in large corporations, where they had felt pressured to trade off performance and career advancement against their family and faith commitments. Reell's Website describes the company's founding principles as follows:

From the beginning, the three partners discussed how to shape and build the company through ethical values and principles. The founders accepted the importance of strong financial performance, but not at the expense of employees' health and families. They envisioned a company in which all coworkers could perform valuable and creative work in an environment that supported their physical, emotional and spiritual health. They built Reell's success by placing a high priority on understanding and serving the needs of coworkers, customers, suppliers and the community. (http://www.reell.com/index.php?page= history)

Reell's three founders also sought to achieve their founding principles with integrity. ${ }^{7}$ Reell's Direction Statement (Table 1) and Declaration of Belief (Table 2) publicly express Reell's philosophical and spiritual foundations, and they articulate what those principles mean for

\footnotetext{
${ }^{7}$ Carter (1996, p. 7) suggested that acting with integrity requires three steps: "(1) discerning what is right and what is wrong; (2) acting on what you have discerned, even at personal cost; and (3) saying openly that you are acting on your understanding of right from wrong" (emphasis in the original).
} 
Table 1 Reell Precision Manufacturing, Inc.'s Direction Statement. (c) Reell Precision Manufacturing, Inc.

\section{Direction statement}

Reell is a team united in the operation of a business based on the practical application of spiritual values to promote the growth of individuals and advance the common good for the benefit of co-workers and their families, customers, shareholders, suppliers, and community. Rooted in Judeo-Christian values, we welcome and draw on the richness of our spiritually diverse community. We are committed to provide an environment where there is harmony between work and our moral/ethical values and family responsibilities and where everyone is treated justly

The tradition of excellence at Reell was founded on a commitment to excellence rooted in the character of our Creator. Instead of driving each other toward excellence, we strive to free each other to grow and express the excellence that is within all of us

By adhering to the following four common spiritual principles, we are challenged to work and make decisions consistent with God's purpose for creation according to our individual understanding

Do what is right

We are committed to do what is right, even when it does not seem to be profitable, expedient, or conventional

Do our best

In our understanding of excellence we embrace a commitment to continuous improvement in everything we do. It is our commitment to encourage, teach, equip, and free each other to do and become all that we were intended to be

Treat others as we would like to be treated

Seek inspirational wisdom

By looking outside ourselves, especially with respect to decisions having far-reaching and unpredictable consequences, but we will act only when the action is confirmed unanimously by others concerned

We currently design and manufacture innovative products for a global market. Our goal is to continually improve our ability to meet customer needs. How we accomplish our mission is important to us. The following groups are fundamental to our success:

Coworkers

People are the heart of Reell. We are committed to provide a secure opportunity to earn a livelihood and pursue personal growth Customers

Customers are the lifeblood of Reell. Our products and services must be the best in meeting and exceeding customer expectations

Shareholders

We recognize that profitability is necessary to continue in business, reach our full potential, and fulfill our responsibilities to shareholders. We expect profits, but our commitments to coworkers and customers come before short term profits

Suppliers

We will treat our suppliers as valuable partners in all our activities

Community

We will use a share of our energy and resources to meet the needs of our local and global community

We find that in following these principles we can experience enjoyment, happiness, and peace of mind in our work and in our individual lives

Source http://www.reell.com/index.php?page=beliefs-values-purpose

Table 2 Reell Precision Manufacturing, Inc.'s Declaration of Belief. (c) Reell Precision Manufacturing, Inc.

\section{Declaration of belief}

We believe the dignity of every individual to be sacred...

We believe life's highest purpose for each individual is to become all that she or he is created to be, and...

We believe the highest purpose for the Corporation is to make worthy contributions to the common good, therefore...

All activities, objectives and policies are to be ordered toward individual development and the common good

Because economic success is essential for an environment that fosters human development and provides for the common good, we must maintain an orderly, efficient and profitable organization and respect the dignity of every individual

Because many spiritual traditions speak powerfully regarding the conditions necessary to provide for the common good, foster individual development and respect human dignity, we will encourage each other to draw wisdom from these traditions and from individual expressions of spirituality

Source http://www.reell.com/index.php?page=beliefs-values-purpose

acting with integrity. The Direction Statement's four spiritual principles in particular encourage each coworker to (1) Do what is right (even when it does not seem profitable or expedient); (2) Do their best (e.g., by encouraging, equipping, and helping one another); (3) Treat others as they would like to be treated; and (4) Seek 
inspirational wisdom (especially when making significant decisions). ${ }^{8}$ The Reell Direction Statement is prominently displayed on its Web site and on plaques in the corporate headquarters' rooms and hallways.

While Reell's four spiritual principles have roots in the New Testament (Wahlstedt 2011), multiple sources of evidence indicate that the company strives to be inclusive and respectful toward other faith traditions. For example, the Direction Statement's first paragraph states, "Rooted in JudeoChristian values, we welcome and draw on the richness of our spiritually diverse community." The company's Declaration of Belief (see Table 2) uses nondenominational and inclusive language to elaborate on the four principles' spiritual roots. Similar themes of inclusiveness continue to be expressed at board and senior leadership retreats (e.g., Wahlstedt 2011). ${ }^{9}$ Reell VP of Coworker Services Ken Rude, after mentioning that Reell has several Hmong employees and an office in Asia, offered his perspective on the company's inclusivity:

One thing that we always want to be clear is that you don't have to be of any spiritual tradition to be a part of Reell. We want people of all faiths, all walks of life, but there are consistent principles and we teach to those principles. Now those principles are rooted in Judeo-Christian values.... I know that there are traditions in the East that follow some of those same dignity of people type of principles: Treating each other well, doing your best, and so you could draw upon those, and I think that fits well within the context of what that coworker [in the East] may have grown up or understood or has been their religious tradition.

\section{Expression of Espoused Values in Practice- Arrangement Meshes}

The above section described how Reell's espoused values are expressed in company documents, communicated throughout

\footnotetext{
${ }^{8}$ Reell's Direction Statement and Declaration of Belief are distinctive but they are not unique. For example, Johnson and Johnson's credo (reproduced in Simons 1995, p. 35) includes features that are similar to Reell's first three spiritual principles.

9 Goodpaster (1999) documented the tensions raised by Reell's spiritual character. Wahlstedt (August 16, 2012 interview) related the story of a Reell engineer who was agnostic and did not accept the founders' religious beliefs. Wahlstedt described it this way: "[The first] non-founder engineer that we hired started in 1985 and shortly thereafter in reading the Direction Statement which at that time just said 'We are committed to follow the will of God'. He came and started off by saying 'I like the company, I like what we're doing, I like the Direction Statement, I want to embrace it, but that phrase doesn't mean anything to me'... [In response] we said it means to do what's right, it means to do your best, it means to treat others the way you would like to be treated... And he said 'Well I can do that, I can understand that.' Then we actually put those words in [the Direction Statement]."
}

the organization, and interpreted by senior management. This section addresses our second and third research questions, which ask "What kinds of evidence indicate that the espoused values shape Reell's human resource activities?" and "How have financial and other resources enabled or constrained Reell's human resource practices, and how have other internal or external practices determined the amount of available resources?", respectively.

\section{Layoff Avoidance Policies}

The Reell (2009, p. 7) Coworker Policy Manual gives the standard "employment-at-will" boilerplate in its assertion that "Neither a coworker nor Reell is bound to continue the employment relationship and either can choose to end the relationship at any time." While some employees have been terminated for cause, during its first 38 years the company did not implement any layoffs due to slack demand for its products and instead took other measures to survive through periods of business decline. ${ }^{10}$ Wahlstedt (undated, p. 10) explained that the company's general policy puts people ahead of profits:

Maintaining full employment and full salary has a higher priority than short term profits. Even when faced with a "loss," our policy is to reduce salaries on a percentage basis rather than to lay off anyone."

(Wahlstedt, undated, p. 10).

This policy toward layoffs is consistent with the company's espoused values to "Treat others as we would like to be treated" and "Do what is right, even when it does not seem to be profitable."

Other conditions besides Reell's espoused values also determined how the layoff avoidance policy was implemented. For example, the company's employee structure and financial constraints shaped how the pay cuts could feasibly be allocated in 1974:

The company was so small then that I think that there were only three other employees [in addition to the

\footnotetext{
${ }^{10}$ For some examples, in 1974 during the company's first business downturn, the founders took a $50 \%$ salary cut while the other employees took 10-20\% cuts; in 1982, shop workers took hourly and pay reductions for 2 or 3 months to adjust for reduced production volume; an across-the-board pay and hiring freeze was implemented for seven months in 1994; and after experiencing a significant reduction in orders from a major customer, a $10 \%$ payroll reduction was implemented for four months in 1996 without a corresponding reduction in hours, with $80 \%$ of the $10 \%$ cut paid back to the employees by the end of the year when business rebounded (see Herrera 2006, pp. 28-32; Naughton and Specht 2011, p. 28; Wahlstedt, undated). During the pay reduction period in 1996, Reell's senior executives took the biggest cuts and employees who were at or under the company's target wage were exempt from the wage cuts (Alford and Naughton 2001, p. 147).
} 
three founding executives]. Laying off everyone wouldn't have done it, nor could we stay in business if we laid off everyone...There just wasn't any money for us [three executives] to take our full salary... It never crossed my mind that I had any choice. (Bob Wahlstedt)

This example illustrates that Reell's layoff avoidance activities must be understood as taking place within a "mesh of practices and arrangements" (Schatzki 2003, pp. 191-192), in which multiple internal and external practices shaped and were shaped by Reell's available financial resources. ${ }^{11}$

\section{Public Articulations of Layoff Policies}

Shared understandings play a prominent role in Schatzki's ontology of social practices. Managers can periodically communicate with subordinates about the relation between company policies and espoused values (cf. the interactive control systems in Simons' (1995) framework). As such, it can be just as important for a company to "talk the walk" as it is to "walk the talk." At Reell, senior management has from time to time invoked Reell's espoused values to advocate specific layoff avoidance activities, and various internal documents describe how those values have shaped its previous layoff avoidance policies.

For example, the 2001 economic downturn was problematic for Reell because of its severity, uncertainty about the size and timing of the eventual recovery, and the company's preceding debt-financed expansion of physical facilities. These difficult circumstances prompted Jim Grubs (the VP of Coworker Services back then) to write a March 2001 memo about the dilemma in light of Reell's Direction Statement and Declaration of Belief, and in which he recommended that Reell continue with its wagereduction strategy: ${ }^{12}$

The value of freedom to choose is paramount to the dignity of the individual; it is an underlying principle of the Human Rights Charter of the United Nations drawn up in Helsinki, Finland. When you tell an individual he or she must leave, then you tear at the very fabric of their dignity-it is no longer a choice... At the same time I am very mindful of the Declaration of Belief's commitment toward the common good and our clear need to have a

\footnotetext{
11 A later section elaborates on the practices-arrangement theme, whereby Reell's available financial resources shaped and were shaped by its human resource practices, financial management practices, other internal operating practices and decisions, and the operating practices of Reell's external competition.

12 The complete memo is reproduced in Naughton and Specht (2011, pp. 30-32).
}

corporation that survives. For if we have no corporation, then we lose our ability to make "worthy contributions to the common good... It is my belief we currently need to continue with the wage-reduction strategy."

In addition to other cost-reduction measures in 2001, Reell eventually took a $12-16 \%$ pay reduction for senior executives in January, followed by a $7 \%$ pay reduction in March for most coworkers except those who earned less than the target wage, and no reduction in hours.

In addition, the Reell Guidance Manual (2003, pp. 1-2; quoted in Herrera 2006, p. 28) included these statements about Reell's general policy toward layoffs:

In the history of Reell, we have never laid anyone off or let anyone go due to a short-term change in business conditions. There have been many times when we have found it necessary to freeze pay and even reduce pay in order to protect our long term future. When this happens, we all share the burden rather than letting people go or laying people off.

Moreover, Reell's Web site describes the events of 2001 as follows:

Win-win outcomes became difficult to define in 2001, with over a $30 \%$ decline in revenues. Reell's commitment to its coworkers made it unthinkable to institute layoffs as long as other alternatives existed. Profits were allowed to go to zero. Pay reductions were initiated for all except those below the target wage, with senior management taking the largest cuts. Dividends were reduced. These actions combined to allow the company to stay at or slightly above breakeven without layoffs. Business came back in 2002 and 2003 and Reell was well positioned to capitalize on this opportunity with its workforce intact. But even more important, the emotional and spiritual trauma of layoffs was avoided. Reell was recognized for this "unusual" response with the Minnesota Business Ethics Award in April of 2003, and the National Business Ethics Award in early 2004. (http://www.reell.com/index.php?page=history)

These and other communications create shared narratives and understandings about how the company's espoused values are integrated with its practices and thereby also reinforce the values.

\section{Job Descriptions and Performance Reviews}

Reell's values-shaped human resource practices include many other activities and supporting documents. Reell's job descriptions, Annual Conference Form, and Coworker 
Policy Manual each explicitly refer to the Direction Statement's principles, and each reinforces the shared understandings, rules, and teleoaffective structures that coworkers are expected to bring to bear on their work. The following detailed examples illustrate how espoused values can be embedded in and reinforced by the organization's activities.

Reell's job descriptions list "Primary Characteristics" first, whose first bullet point is "Principles: Supports and models the company's principles that are identified in the Declaration of Belief and Direction Statement, in all areas of conduct and business." Furthermore, Reell's employee retention and layoff avoidance policies do not preclude termination for substandard performance. As at most other companies, annual reviews are designed to enable coworkers to address identified performance problems:

If your advisor's perception was that your performance was substandard, was not adequate, that was a perception that had to be dealt with. This process would lead either to a correction of that perception if it was wrong, correction of the performance, or termination. I personally remember terminating about four people... There never was a policy that said we would indefinitely absorb the costs of substandard performance. (Bob Wahlstedt)

Coworkers who violate the company code of conduct also may be terminated.

The 2011 Annual Conference form (still in use) includes a header on p. 2 that states "Reell... called to a higher behaviors standard... consistent with our Direction Statement and Declaration of Belief." It makes no other reference to the company's spiritual principles, but it includes a coworker and advisor rating on "Servant Leadership" with the following preamble:

At Reell we desire that all coworkers model servant leadership. Everyone is a leader in their own way and a servant leader serves with great humility. It is our desire to serve and meet the needs of those we come in contact with (i.e., fellow coworkers, customers, suppliers...) An important part of servant leadership is creating conditions for people to grow and develop through their work. Servant leaders show a desire to teach, equip and trust their fellow workers.

The 2007 Annual Conference Review form more explicitly engaged with the company's spiritual principles, as in the following preamble:

Each coworker will also be evaluated against the first three key components of the Direction Statement [Do what is right; Do your Best; Treat others as you would like to be treated]. The evaluation of the Seek
Inspirational Wisdom point will be at the discretion of the coworker."

The last page of the 2007 Annual Conference Review form also asked each coworker to define what each of the first three principles meant to them, with examples of how they lived out the principles in their daily work. Finally, it listed the "Seek Inspirational Wisdom" principle with the following statements:

Due to the sensitivity and complexity of this principle, it will not be evaluated. We encourage the Advisor and Advisee to discuss this principle if the Advisee wishes.

While the current Annual Conference Review form less prominently features the "Seek Spiritual Wisdom" principle, Reell now engages in other activities to communicate and reinforce its commitment to living out the principles in everyday practice. The annual Founders' Award is a prominent example.

\section{Coworker Recognition: Annual Founders' Award}

Reell's annual Founders' Award illustrates how shared understandings can be established, promoted, and sustained through the actions that compose practices. It also illustrates how agents in an organization may discuss and deliberate among themselves to achieve consensus about what their organization's espoused values mean and how they are enacted in actual practice.

More specifically, the award recognizes a coworker whose everyday action and character help Reell fulfill its Direction Statement. The nomination form instructs nominators to "Identify examples of characteristics identified in our Direction Statement and exhibited by the Nominee," and "Describe a specific circumstance to illustrate how these characteristics were demonstrated (tell the story to illustrate how they 'lived-out' the Direction Statement)." Any coworker except the CEO and VP of Coworker Services (now called the Director of Global Coworker Services) can be nominated (Reell undated). Past nominations for this award describe how the nominees generously serve their coworkers, customers, or vendors when performing their daily operating activities. Three former award recipients choose the award recipient and use whatever evaluation and selection method they feel is most beneficial. The five most recent Founders' Award recipients were a quality coworker based in Shanghai, a customer service coordinator, an executive administrator, an administrative assistant in operations who also served as a buyer, and the Director of Quality.

The award is presented annually at an Appreciation Lunch. The recipient receives a recognition plaque and has 
his or her name engraved on a plaque located in the Founders' (board) room. The 90-min 2012 Reell Appreciation Lunch event began with the following activities (presenters): Brief review of the Founders' Award (Director of Global Human Services Shari Erdman), the Reell Direction Statement (CEO Kyle Smith), Declaration of Belief (Founding Executive Bob Wahlstedt), announcement of the 2012 Founders' Award (Bob Wahlstedt), an open microphone to acknowledge the recipient (coworkers), and other service recognition awards (Shari Erdman and Kyle Smith). After the Appreciation Lunch another lunch is held to recognize the other Founders' Award nominees. That lunch is attended by all coworkers who were nominated along with the Founders, three past recipients, and the Director of Global Coworker Services. At the lunch event a summary of each nomination is read aloud.

Financial Constraints and their Internal and External Origins

We now address our fourth research question, which asks "What past mistakes have Reell's managers made in putting the espoused values in practice, and how is the reflection on those mistakes shaped Reell's subsequent human resource and financial management practices?" Schatzki's ontological assertions about practice-arrangement meshes indicate that an organization's ability to put its espoused values into action will be enabled or constrained by the available resources, and moreover that the organization's practices and resources mutually shape (codetermine) each other. Indeed, resource constraints and the practices that shaped them meant that Reell's espoused values and preference toward layoff avoidance did not always succeed in preventing layoffs. In the midst of the 2008 economic recession and declining revenues, and after much deliberation and consultation with the board, senior management implemented Reell's first series of layoffs in 2008-2009 due to lack of sufficient demand for its products.

Ken Rude described the layoffs in light of Reell's espoused values; the company's shared understanding about how to implement the layoffs, and the inherent uncertainties in layoff decisions:

When you talk about involuntary separations or dismissals it definitely will affect...the coworker who is being dismissed, it's going to affect those coworkers who remain here at Reell, and it definitely will affect the culture and identity of the organization... But when we go through those [layoffs] it's very important to understand what's leading up to that decision...is it the need at the time, the right time, and can leaders take courageous steps when we ultimately need to? And then just as important, how the dismissals are conducted is vitally important as well.... We want to be as consistent as possible from previous principles that the founders helped lead this organization in the first 30 years of its existence...We want to be consistent in our principle yet again the form might be a little different through these economic conditions.

With the benefit of hindsight reflection, each interviewee acknowledged that the financial consequences of some of the company's earlier business decisions had put the company in a vulnerable position in 2008-2009:

I think the layoffs were required...I think that the situation that Kyle inherited gave him no alternatives. The balance sheet was essentially drained dry, the bank was threatening to foreclose, the decisions that he made to survive 2009 I would not question. (Bob Wahlstedt)

Some of those earlier business decisions included the previous debt-financed doubling of physical plant that was undertaken with the expectation of significant revenue growth. ${ }^{13}$ The 2008 economic recession and the company's high debt burden threatened the company's ability to remain a going concern. Kyle justified the company's first layoffs in these terms:

The easy answer of "well we'll go until we break even"...My analogy is, if I'm in a jet, and we're losing altitude, you can traject when the fuselage is going to hit the ground. I'm not going to run it into the ground before I pull up on the yoke. The more cash that we have and the more fiscal health that we have, I've got more altitude as we're coming down to make adjustments that aren't quite as drastic and so forth...But I'm not one that's going to let it hit the ground and blow up before I pull up on the yoke... I want more elevation so that we have plenty of time for the board, the management team, etc. to react, engage the bankers... I'm not going to wait until we're two steps from bankruptcy before we pull that trigger. So this idea that [layoffs are always] the last resort, there's nothing else left, the company folds up or [conducts] layoffs, I'm not there. (Kyle Smith)

After the layoffs, Kyle also led the company to implement more conservative and proactive financial management and growth policies, all of which he hopes will put the

\footnotetext{
13 Reell's previous CEO pursued a high-volume, low-margin product strategy that later proved highly susceptible to pressure from competitors. Even before the 2008 recession, increasing globalization made Reell's product lines more vulnerable to competition, as it gave their major customers more supply sources.
} 
company in a better position to implement its previous layoff avoidance policies:

We were already a starved cow going into the famine when '09 hit. Well we're not a starved cow now. For our size company we have stored up a fair amount of cash and we're careful how we use that. Debt, I've paid down a bunch of debt, I don't want to be big time in debt, highly leveraged, low cash position because then any little blip out there forces those decisions. That's probably been the single biggest thing, of just saying "guys, let's be prudent, when the sun shines let's make hay and put some in the barn." Yes, it's conservative, and it may limit some of our growth vs. higher risk higher growth opportunities. There have been a lot of discussions with the board, saying we can't be all things guys. It will limit our rate of growth and that's something that we think right now is a prudent tradeoff. We are still growing and we want to continue to grow but it won't be at exceptional rates. (Kyle Smith)

In addition to these more conservative financial and growth policies, under Kyle's leadership Reell has pursued a lower volume, higher margin, and more diversified product strategy with an emphasis on quality and service. But the same strategies also constrain some coworkers' career development opportunities:

We're not able to grow at a fast enough rate to be able to invest in areas that we want to invest in...in order to make sure that we have positions for people to grow into. We've had a few people leave because there was no more opportunity for them [here] (Shari).

The 2008 recession also led Reell managers to reevaluate their previous internal promotion policies which were well intentioned but in some cases had promoted coworkers to positions that they weren't fully prepared to perform. During 2008-2009 some of those coworkers were reassigned to positions that were one or two grade levels below their previous positions, with correspondingly lower pay. In 2013, some of these reassigned coworkers still were making lower wages than they used to make. In addition, some of the coworkers who were laid off were unable to find jobs that paid as well as the jobs they once held at Reell. This was another unintended consequence of Reell's well-intentioned but imperfectly implemented internal promotion policy. As Shari described it, "We want to do 'growth and development' of our coworkers the right way today."

After the 2008-2009 layoffs and job reclassifications, some of the remaining coworkers openly wondered whether the company remained committed to job security and coworker development. Reell's annual coworker surveys document these perceptions.

\section{Reell's Humanizing Values: Coworker Perceptions}

The preceding examples indicate that Reell coworkers generally are well aware of their company's espoused values and are encouraged to reflect on them from time to time. We now address our fifth and last research question, which asks “How do Reell's lower level coworkers perceive the impact of the company's espoused values on their work and personal life?" As a threshold matter, prospective coworkers are exposed to Reell's espoused values even before they are hired. For example, Reell's interview process explicitly raises the values in the Direction Statement. Shari described this part of the interview process as follows:

Sometimes they just don't reference the Web site, and then I specifically draw on the Website, if they've seen it, and if they've seen it and they still don't call out the values, eventually I get around to talking about who we are as a company, how we treat people, how we try to engage coworkers.

In light of these company activities, it is reasonable to expect that coworkers will be able to competently answer questions about how they perceive Reell's espoused values in practice, after they have been hired.

Herrera (2006, pp. 10-11) reported anecdotal evidence that lower level Reell coworkers believed that the company was committed to maintaining and putting into practice an inclusive spiritual philosophy. For more recent evidence, Reell offers its coworkers an annual board-directed survey that it administers voluntarily and anonymously through Survey Monkey. Each year Reell management provides a summary of the survey results at a company-wide meeting. The top of Table 3 lists the 16 survey questions that address the relation between Reell's espoused values and practices. Coworkers indicate their responses to these questions on a 7-point Likert scale ranging from "Totally Inconsistent" (1) to "Neither" (4) to "Totally Consistent" (7), with an opportunity to indicate "Not Applicable." The bottom of Table 3 lists questions that give coworkers an opportunity to elaborate with open-ended comments.

Seventy-one respondents ( $\sim 75 \%$ of coworkers) completed the 2012 survey. The results were generally favorable, with average responses on 16 questions ranging from 5.32 to 6.00 , and with an overall average of 5.65 . $^{14}$ The

\footnotetext{
${ }^{14}$ While most survey data are from lower level coworkers, some data are from senior management. Survey anonymity precludes separating out the senior management data. Only two out of 71 respondents on the 2012 survey optionally provided their names.
} 
Table 3 Reell Precision Manufacturing, Inc.'s Annual Coworker Survey (last revised July 2011)

Coworkers indicate their responses to the following questions on a 7-point Likert scale:

1. Reell provides an environment where I can resolve conflicts between my work responsibilities and my moral/ethical values and family responsibilities

2. Everyone is treated justly

3. At Reell, I have the opportunities to grow as a person and develop my skills and talents

4. We try to do what is right, even when it does not seem to be profitable, expedient, or conventional

5. As a company, we are committed to excellence in everything we do

6. At our company, we encourage, teach, equip and free each other to do and become all that we are intended to be

7. We treat others like we would like to be treated

8. We seek and encourage coworkers to bring to work inspirational wisdom from sources outside ourselves

9. Reell provides a secure opportunity to earn a livelihood and pursue personal growth

10. Reell's products are the best in meeting and exceeding customer expectations

11. Reell puts commitment to coworkers before short-term profits

12. Reell's suppliers are treated as valuable partners in all of our activities

13. We provide a fair share of our energy and financial resources to meet the needs of our local and global community

14. Reell works for the "common good" by integrating the needs of coworkers and their families, customers, shareholders, suppliers and community

15. Reell coworkers are treated with dignity and respect

16. I would recommend Reell to friends or family members as a great place to work

The survey also includes the following open-ended questions:

1. Challenge for Reell: If you could select one thing to change at Reell, what would it be? How would you improve Reell?

2. When I look to "my" future as a Reell Coworker, my biggest concern for me would be:

(a) My salary; (b) Overall benefits; (c) Future opportunities; (d) Job security; (e) Other

Comments:

3. How do you view Reell's "growth" rate?

(a) It is never enough. (b) We are growing at an acceptable and healthy rate. Growth is important, but we should consider other factors as minimizing debt and maintaining profitability and not get fixated merely on growth. (c) We are investing too much in order to attain growth—growth is not a necessity

Further comments:

The 2012 survey yielded a $75 \%$ response rate

highest scores in 2012 were for Question 1 (6.0: harmony among Reell's values at work and family responsibilities); Question 10 (6.0: meeting customer expectations); and Question 15 (5.9: Reell coworkers are treated with dignity and respect). Across the 2012 survey's 16 questions, the number of respondents rating the questions in the lower three categories ranged from 1 to 9 , with an average of 4.3 (6\% of survey respondents). ${ }^{15}$ Over the $1998-2012$ period, the average annual scores on each of the 16 questions ranged from 4.5 to 5.7 out of 7. Data for each of those separate years yielded qualitatively similar results, except

\footnotetext{
15 With the survey's anonymity we cannot definitively attribute most of the lower ratings to lower level coworkers. A study by Ardichvili et al. (2012), however, suggests that lower level coworkers probably did provide the majority of the lower ratings. Specifically, the study surveyed more than 40,000 people from different hierarchical levels in business organizations in six countries and found that executives gave the most positive assessment of their organization's ethical business culture, followed by mid-level managers and then by lower level employees who gave less positive assessments (Ardichvili et al. 2012, p. 348)
}

that the 2008 survey (which was administered at the end of the year of Reell's first layoffs in its 38 year history) understandably yielded some of the lowest average responses.

Finally, the lowest scores in 2012 were for Question 2 (5.4: everyone is treated justly) and Question 9 (5.5: Reell provides a secure opportunity to earn a livelihood and pursue personal growth.) The 2012 survey thus indicates that some coworkers continued to be concerned about their job security and career growth opportunities. Responses to the open-ended 2012 survey questions further substantiate these concerns. Specifically, of the 22 respondents to "If you could select one thing to change at Reell, what would it be?" four suggested that steps should be taken to increase revenue and wage growth. ${ }^{16}$ Of the 67 respondents to "When I look to my future as a Reell Coworker, my biggest concern would be [select one:]...," 54 (81\%) selected

\footnotetext{
16 The majority of the other respondents gave operational suggestions, such as "Expand product line width" or "More product/catalog exposure through advertising."
} 
"My salary" (21), "Future opportunities" (18), or "Job security" (15). In addition, 17 of the 18 respondents who gave open-ended comments elaborated on the salary, opportunity, job security, and revenue growth themes. Finally, of the 67 respondents to "How do you view Reell's 'growth' rate?" 16 selected the "It is never enough" option and the other 51 selected the "We are growing at an acceptable and healthy rate" option. In addition, 11 of the 19 respondents who gave open-ended comments elaborated on their wish for more company growth.

Altogether, the 2012 survey data indicate that most coworkers hold favorable perceptions about Reell's values and practices, and are consistent with anecdotal evidence reported by Herrera (2006). The 2012 survey data also indicate that a minority of coworkers are concerned about how Reell's recent and openly communicated conservative growth policies will affect their job security, salary, and career advancement opportunities.

\section{General Discussion}

This study provided a conceptual framework for theorizing about values/practice linkages in general, and then applied the framework in a case study of how Reell, a small to medium sized privately held manufacturer, attempts to live out its espoused values in its everyday practices. We first located our values/practices focus within Simons' management accounting and control framework, which posits that organizations employ belief systems, boundary systems, diagnostic control systems, and interactive control systems to help agents achieve their organization's strategic objectives. The belief and boundary systems in Simons' framework encompass values, and the diagnostic and interactive control systems can incorporate some valuesbased practices, but the framework's emphasis on information and strategy incompletely addresses the shared understandings, norms, affective characteristics, and other interrelated components that link values with organizational practices. Accordingly, we adapted Schatzki's (2002, 2003, 2005) site ontology to develop general research expectations for case studies of values/practices linkages.

Schatzki's framework has several advantages for the study of values in organizational practices. First, it posits that an organization's values will be linked with its practices through agents' shared understandings about their activities, rules that prescribe how things must be done or said in the organization, and the range of acceptable or prescribed organizational objectives, projects, and uses of things. Second, while Schatzki's ontology posits that values will shape practices, it also leaves open the possibility that an organization's operative values may violate its espoused values. Indeed, public declarations of good intentions in an organization's mission and vision statements are not by themselves sufficient to enact those intentions in actual practice. The social and environmental accounting literature, for example, has documented the organizations' mission statements and narrative self-reports often give misleading accounts of their activities and outcomes (cf. Gray 2010, pp. 252-255). Just as individuals will often control and publicly display their behavior in a manner that they think best fits the situation (Goffman 1959, Chap. 1; Goffman 1963, pp. 16-30), organizations may engage in dramaturgical action to strategically manage the public's perception that the organization's structure, agenda, and activities are consistent with other agents' cherished values and objectives (c.f. Ritti and Silver 1986, p. 28). Finally, Schatzki's ontology recognizes that an organization's practices may be enabled or constrained by its available resources, and that the resources may in turn be partly determined by internal or external practices. An organization's ability to effectively enact a healthy tone at the top requires more than a positive organizational culture; it also requires (for example) a sufficiently profitable business model to sustain the organization through lean times.

Empirically, Schatzki's framework indicates that a case study of an organization's values/practices linkages should include evidence about such matters as the organization's professed values; how and where the values are communicated throughout the organization; the resources that the organization uses to support its values-based practices; and how the values and resources shape the organization's practices. We chose Reell for our case study because previous case studies had indicated that its espoused values aim to create a humanizing organizational culture, and that some of its past practices reflected those values. Our case study described and analyzed the company documents that express Reell's espoused humanizing values; multiple examples of how the values shape and are reinforced by the hiring, annual review, annual coworker recognition, and other activities that comprise of Reell's human resource practices; how financial constraints have shaped Reell's human resource practices and operating strategies; past mistakes that Reell's managers made in putting the company's espoused values into practice and how reflection on those mistakes has shaped Reell's subsequent practices; and annual survey data showing that most coworkers favorably perceive their company's values and practices, but also that a minority of coworkers are concerned about how the company's current strategy of conservative growth may adversely impact their job security, future compensation, and career advancement.

Altogether, this paper's conceptual framework and case study contribute to the tone at the top/organizational practice literature by exploring a larger set of values and 
objectives than are commonly considered in the enterprise risk management literature; by conceptualizing the linkages among values and practices in more detail than in the management accounting and control literature; and by describing examples of values/practices linkages from an actual organization in more detail than in some widely promulgated codes of ethical business conduct.

The Study's Limitations and the Opportunities They Raise for Future Research

We conclude by identifying three limitations of our study and some related opportunities for future research. First, our case study emphasized how Reell's espoused values have shaped its human resource practices, and it described how some of Reell's activities reinforced its values, but it did not emphasize how Reell's activities shaped or modified its values. More research on the mutual shaping of organizational values and activities would contribute to our knowledge of how an organization's practices and related outcomes can reflect, reinforce, or violate the organization's espoused values. This approach could be used, for example, in studies of how a shift in operating conditions, personnel, and organizational practices may alter an organization's values, such that the organization's emerging operative values eventually conflict with its publicly espoused values.

Second, our case study of Reell focused primarily on the documents, policies, and activities that comprise its human resource practices, and did not specifically set out to examine the characteristics of the specific agents who carry out the company's activities. The spiritual origins of Reell's espoused values indicate how the personal commitments of an organization's leaders can play a significant role in defining and enacting the organization's humanizing commitments. Knowledge of the dynamics and tensions of organizational values/practices linkages would be enhanced by future research on how agency and structure together shape organizational systems and how agents manage conflicts among their personal and professional commitments. For example, while private and mutual interests may coincide under ideal circumstances in a wellfunctioning society (cf. Douglass 1980, p. 105; Lewis 2006 , p. 698), conflicts often arise between personal commitments and codified professional codes of conduct (cf. Martin 2000, p. 49), and between the welfare of specific individuals and the general welfare of society (cf. Care 1984; Douglass 1980; Martin 2000, pp. 6-7, 46; Williams 1981, Chap. 5). These conflicts can be further exacerbated by the view that professionals should set aside their personal values, feelings, and commitments in order to best meet their professional responsibilities (for a critique of this view, see Martin 2000, Part 1). Future research could conceptually and empirically examine the mix of personal and professional commitments that would best support business professionals' ability to engage in activities that advance the public interest.

Third, our study briefly considered the external competitive and lending pressures that have constrained Reell's ability to fully enact its values-driven job security and coworker development objectives. Schatzki's ontology recognizes that practices can be linked to other internal and external practices. For accountants, one implication is that effective risk management at an organizational level will at least partly depend on the larger constellation of societal and global risk management practices and resources within which the organization operates. Indeed, analyses of the 2008 global financial crisis indicate that enterprise risk management frameworks oversold their ability to help agents, organizations, and markets create and sustain wellordered organizations and societies (cf. Hopwood 2009, p. 798; McSweeney 2009, pp. 839-840; Power 2009). Future research that examines practice-arrangement meshes across organizations and societies would advance our knowledge of agent-structure interactions and the efficacy of an organization's tone at the top in an increasingly interdependent and global world.

Acknowledgments We gratefully acknowledge the comments and suggestions from two anonymous reviewers, participants in the 1st Biennial Symposium on Accounting Ethics (Waterloo Accounting and Finance Centre for Accounting Ethics, Toronto, CA), Ron Strauss and Louise Lalonde (discussants), and Gajie Maharaj. We also thank the coworkers at Reell Precision Manufacturing, Inc. who participated in interviews and granted access to company documents. The University of St. Thomas Institutional Review Board granted human subjects approval for this study (IRB Tracking Number 297890-1). Funding for this research was provided to the first author through grants provided by the University of St. Thomas Sabbatical Leave Program and the Opus College of Business Veritas Institute, Center for Ethical Business Cultures, and Summer Research Award Program. Michael Naughton also served as Chair of the Board of Reell Precision Manufacturing, Inc. (the subject of our case study) when this research was conducted. His familiarity with Reell was instrumental in gaining access to company personnel and documents. He received a monthly stipend for his board services and does not own Reell company stock.

\section{References}

Ahrens, T., \& Chapman, C. S. (2007). Management accounting as practice. Accounting, Organizations and Society, 27, 1-27.

Alford, H. J., \& Naugton, M. J. (2001). Managing as if faith mattered. Notre Dame, IN: University of Notre Dame.

Ardichvili, A., Jondle, D., \& Kowske, B. (2012). Minding the gap: Exploring differences in perceptions of ethical business cultures among executives, mid-level managers and non-managers. Human Resource Development International, 15(3), 337-352.

Berg, B. L. (2004). Qualitative research methods for the social sciences (5th ed.). New York: Pearson Education. 
Care, N. S. (1984). Career choice. Ethics, 94(January), 283-302.

Carter, S. L. (1996). Integrity. New York: HarperCollins Publishers.

Caux Round Table. (2010). Principles for business. Retrieved January 12, 2013, from http://www.cauxroundtable.org/index.cfm?\&me nuid $=8$.

Committee of Sponsoring Organiztions of the Treadway Commission (COSO). (2004). Enterprise risk management-integrated framework. New York, NY: American Institute of Certified Public Accountants.

Douglass, B. (1980). The common good and the public interest. Political Theory, 8(1), 103-117.

Englund, H., Gerdin, J., \& Burns, J. (2011). 25 years of Giddens in accounting research: Achievements, limitations and the future. Accounting, Organizations and Society, 36, 494-513.

Gendron, Y., \& Barrett, M. (2004). Professionalization in action: Accountants' attempt at building a network of support for the WebTrust seal of assurance. Contemporary Accounting Research, 21(3), 563-602.

Goffman, E. (1959). The presentation of self in everyday life. New York: Doubleday.

Goffman, E. (1963). Behavior in public places. New York: The Free Press.

Goodpaster, K. E. (1999). Reell Precision Manufacturing, Inc. (A). St. Paul, MN: University of St. Thomas. (Also published in Goodpaster, K. E., Nash, L. L., \& de Bettignies, H. -C. (2006). Business ethics: Policies and persons, (pp. 151-166). New York: McGraw-Hill Irwin.

Goodpaster, K. E., \& Naughton, M. J. (2004). Reell Precision Manufacturing, Inc. (E1): Ten years later. St. Paul, MN: University of St. Thomas.

Goodpaster, K. E., \& Naughton, M. J. (2005). Reell Precision Manufacturing, Inc. (E2): Ten years later. St. Paul, MN: University of St. Thomas.

Gray, R. (2010). Is accounting for sustainability actually accounting for sustainability.... and how would we know? An exploration of narratives of organizations and the planet. Accounting, Organizations and Society, 35(1), 47-62.

Herrera, D. (2006). Reell Precision Manufacturing (Reell): A successful value-based, high-tech organization grounded on shared employee ownership, coworker participation in decision making and self-management. Presented at the 13th Conference of the International Association for the Economics of Participation, Mondragon University, Basque Country, Spain. Working paper, San Diego, CA: University of San Diego.

Hopwood, A. G. (2009). The economic crisis and accounting: Implications for the research community. Accounting, Organizations and Society, 34(6-7), 797-802.

Lewis, C. W. (2006). In pursuit of the public interest. Public Administration Review, 66(5), 694-701.

Martin, M. W. (2000). Meaningful work: Rethinking professional ethics. New York: Oxford University Press.
McSweeney, B. (2009). The roles of financial asset market failure denial and the economic crisis: Reflections on accounting and financial theories and practices. Accounting, Organizations and Society, 34(6-7), 835-848.

Mele, D. (2003). Organizational humanizing cultures: Do they generate social capital? Journal of Business Ethics, 45, 3-14.

Naughton, M., \& Specht, D. (2011). Leading wisely in difficult times: Three cases of faith and business. New York: Paulist Press.

Organization for Economic Cooperation and Development (OECD). (2008). Guidelines for multinational enterprises. Retrieved January 12, 2013, from http://www.oecd.org/department/0,3355, en_2649_34889_1_1_1_1_1,00.html.

Power, M. (2009). The risk management of nothing. Accounting, Organizations and Society, 34, 849-855.

Reell Precision Manufacturing, Inc. (2003). Guidance manual. Vadnais Heights, MN: Reell Precision Manfuacturing, Inc.

Reell Precision Manufacturing, Inc. (2007). Annual conference review. Vadnais Heights, MN: Reell Precision Manufacturing, Inc.

Reell Precision Manufacturing, Inc. (2009). Coworker policy manual. Vadnais Heights, MN: Reell Precision Manufacturing, Inc.

Reell Precision Manufacturing, Inc. (2011a). 2011 annual conference. Vadnais Heights, MN: Reell Precision Manufacturing, Inc.

Reell Precision Manufacturing, Inc. (2011b). Founders' award application. Vadnais Heights, MN: Reell Precision Manufacturing, Inc.

Reell Precision Manufacturing, Inc. (Undated). Founders' Award Process. Vadnais Heights, MN: Reell Precision Manufacturing, Inc.

Ritti, R. R., \& Silver, J. H. (1986). Early processes of institutionalization: The dramaturgy of exchange in interorganizational relations. Administrative Science Quarterly, 31, 25-42.

Schatzki, T. (1997). Practices and actions: A Wittgensteinian critique of Bourdieu and Giddens. Philosophy of the Social Sciences, 27(3), 283-308.

Schatzki, T. (2002). The site of the social: A philosophical account of the constitution of social life and change. University Park, PA: Pennsylvania State University Press.

Schatzki, T. (2003). A new Societist social ontology. Philosophy of the Social Sciences, 33(2), 174-202.

Schatzki, T. (2005). Peripheral vision: The sites of organizations. Organization Studies, 26(3), 465-484.

Simons, R. (1995). Levers of control: How managers use innovative control systems to drive strategic renewal. Boston, MA: Harvard Business Review Press.

Wahlstedt, R. (2011). Examining the roots of our founding documents. Presentation at the Reell Board/Reell Leadership Team Retreat (November 17-18). Vadnais Heights, MN, USA.

Wahlstedt, R. (Undated). History of Reell. Vadnais Heights, MN.

Williams, B. (1981). Moral luck. Cambridge: Cambridge University Press. 